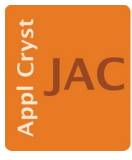

JOURNAL OF APPLIED CRYSTALLOGRAPHY

ISSN 1600-5767

eywords: book review; metals; alloys.

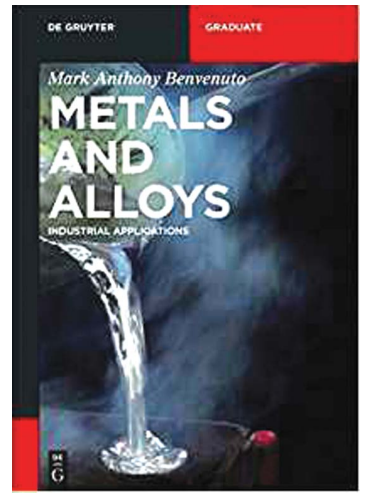

(C) 2018 International Union of Crystallography

\section{Metals and Alloys: Industrial Applications. By Mark Antony Benvenuto. DeGruyter, 2016. Pp. 153. Price EUR 69.95, USD 98.00, GBP 52.99. ISBN 978-3-11-040784-6.}

\author{
Dominique Daloz*
}

Université de Lorraine, École Nationale Supérieure en Génie des Systèmes et de l'Innovation, 8 rue Bastien Lepage, 54000 Nancy, France. *Correspondence e-mail: dominique.daloz@univ-lorraine.fr

Metals and alloys proposes to introduce the reader to the importance of metals in everyday life. To accomplish this the author has chosen to present a set of metals, some well known to the public and some less so, each selected because they 'have applications that help enable people today to live a quality of life that humanity has not previously achieved'.

In a short introduction (four pages) the author describes the role of metals within ancient civilizations (Bronze Age, Iron Age...) and the growing use of metals at larger scales, concomitant with the Industrial Revolution. He points out the discovery of new elements in the 18th and 19th centuries and the variety of their applications, from niche to major uses. The importance of recycling and re-use of metals is also described.

The book is then made up of 21 short chapters averaging six pages apiece, each describing a particular metal. The choice of the order of the metals presented in these chapters is not very well understood by this reviewer [Cu, Sn, Zn, 'pewter', $\mathrm{Au}, \mathrm{Ag}, \mathrm{Fe}, \mathrm{Pt}$, $\mathrm{Ni}, \mathrm{Al}, \mathrm{Ti}, \mathrm{Mg},(\mathrm{U}, \mathrm{Th}$ ), Am, Hg, 'lanthanides', $\mathrm{Pb}, \mathrm{W},(\mathrm{Ta}, \mathrm{Nb})$, Na and finally Li], but this does not ultimately affect the readability or the quality of the work.

Each chapter is built according to the same structure. They begin with a brief introduction to the element describing its discovery, the evolution of its historical application(s), the quantities produced today and the main producing companies. A short analysis places the element in the strategic context of global production. These introductions are generally rich in anecdotes, making these sections useful for capturing the attention of the reader. The bibliography associated with these introductions is also rich in links, allowing the preparation of a more in-depth course if desired. Where possible, the author also mentions if the metal considered is listed as a strategic metal according to the United States Geological Survey, and if international associations exist which are of use to the public or specialists concerning the element.

A second section then specifies the refinement and isolation of the metal. It describes the main ores, their geographical locations and the producing countries. The elaboration and refinement stage of the metal is considered by an examination, in a systematic way, of its extraction and/or enrichment, followed by a succinct description of the corresponding set of chemical reactions concerning purification and separation. When these reactions are too complicated, taking into account the 'non-stoichiometry' of the reactions (for example, americium refinement), only a description of the various operations is given.

Without going into fine detail of the processes or the operating conditions and stoichiometries of the reactions involved, chapter after chapter, the book allows the reader to get a general vision of the extractive metallurgy processes.

A third section then endeavours to describe the main applications of the metal or alloy in question, by attempting to explain the technical reasons why and the properties for which the element under consideration is used (mechanical, chemical, physical...). In this part properties widely known by the general public are presented, together with more specific uses which may be less known, except by specialists (for example, the float glass process for tin, paint pigment for $\mathrm{Zn}$, electronic for $\mathrm{Ag}$, explosive for $\mathrm{Al}$, reducing agent for $\mathrm{Mg}$, superconducting wire for $\mathrm{Nb} . .$.$) . Together these lead to an interesting$ reading of the book. 


\section{book reviews}

A fourth short section is then dedicated to answering the question of possible substitutes for the metal, together with the way and reason why this metal competes with other systems.

The fifth section gives in a few lines an insight into the recycling of the material: the amount of recycling from its different uses (as alloy, as catalyst...) and the economic reasons for it.

A bibliographic review ends every chapter.

Overall the book is written in a concise way. It is well structured and clear. It is illustrated with coloured schematics of statistics which are easily read. Few pictures illustrate the applications (fewer than ten for the whole book), but more are not needed.

A possible weakness of the book concerns the bibliography, $90 \%$ of which is made up of online resources.

As a conclusion, graduate students in materials science as well as first year chemical students are likely to find this book worth reading. I recommend this book for people who want to have a rapid overview of metals or for teachers who want to prepare an introduction to metallurgy. 